\section{P6.09 IDENTIFYING THE BARRIERS SEX WORKERS EXPERIENCE TO PARTICIPATE IN POLICY MAKING DECISIONS IN JOHANNESBURG, SOUTH AFRICA}

${ }^{1}$ Keith Mienies, ${ }^{2}$ Gavin Surgey. 'Wits School of Governance, MPP Candidate, Johannesburg, South African Republic; ${ }^{2}$ Health Economics and AIDS Research Division, Ukzn, Johannesburg, South African Republic

\subsection{6/sextrans-2017-053264.660}

Introduction The basis of a democratic government is consultation and participation by its citizenry in public policy making. Marginalised populations don't have the power and authority due to a lack of agency and a variety of factors. These factors in combination with socio-economic challenges cripple their rights to healthcare policies that is realistic with their needs.

Are sex workers able to participate in policy making in South Africa? And what hinders their participation in the policy making decisions. By having a better understanding of the barriers to participation in the policy making process, we are more readily able to address these barriers for an inclusive consultation of sex workers in future policy work.

Methods This is a qualitative study conducted in South Africa using grounded theory.Data from informants who currently are or have been involved in policy making are collected as well as focus group discussions with sex workers. Informants were asked a series of questions relating to legislation that governs participation in policy making, participation and consultation platforms available to sex workers, social exclusion and stigma experienced by sex workers, the impact of knowledge and education on the ability to participate, agency (political, human and social), the impact of organisation/ mobilisation on participation, identifying their perceived barriers to participation and how to strengthen participation of sex workers in public policy making institutions.

Results and conclusion The barriers identified by both sex workers and key informants to participation of sex workers in policy making includes:

Stigma of sex workers;

Time away from income earning activities

Criminalization of sex work

The political interests of development aid providers

The internal locus of control of sex workers

Lack of political support

\section{P6.10 INTERVENIENT FACTORS IN THE NOURISHMENT OF CHILDREN VERTICALLY EXPOSED TO HIV}

Marília Alessandra Bick, Cristiane Cardoso de Paula, Stela Maris de Mello Padoin, Polyana de Lima Ribeiro. Universidade Federal de Santa Maria, Santa Maria - RS, Brazil

10.1136/sextrans-2017-053264.661

The vertical transmission control after birth is passed to the child's caregiver, having them ties of consanguinity or not, once the child does not promote self-care itself. When supported and guided by health professionals, it is the caregiver who has the power to ensure the prevention and improvement of the child's quality of life. However, when these guidelines are insufficient or inadequate, the children receive nourishment that do not supply their nutritional needs, the deficiency of adequate information about the nourishment of children vertically exposed to HIV, its common. The guidelines effectiveness is directly related to the psychosocial, cultural and biological specificities of each family, and to comprehend them, it is necessary that health professionals have an approach of the reality experienced by them, through the settlement of a relationship of bond and respect. It is known that there is a variability of factors that influence in a positive or negative way on the food choices offered to children exposed to HIV. This study has as a purpose to evaluate the available evidences in scientific articles about the intervenient factors in the nourishment of children vertically exposed to HIV. It's an integrative revision of the literature, performed on the LILACS, PubMed and Scopus data bases, in January 2016. 29 primary studies evidenced the factors that interfere in the nourishment of these children: on the individual surface, the maternal feelings and desires, beliefs and practical difficulties. On the social surface, the socioeconomic conditions, social support and prejudice. On the political surface, the services' structure and organisation, input supplies, guidance and the professionals' empathy and ethics. The factors that interfere in the nourishment of vertically exposed children may be independent or associated to each other. For the risks of inadequate nutrition and associated diseases to be reduced, action is needed to identify and minimise these factors, guaranteeing the promotion of health and reduction of infant morbimortality.

\section{P6.11 STEMMING THE TIDE OF RISING SYPHILIS IN THE UNITED STATES (U.S.)}

Melissa Habel, Karen Kroeger, Gail Bolan, Sevgi Aral. Centres for Disease Control and Prevention, Atlanta, USA

\subsection{6/sextrans-2017-053264.662}

Introduction In the U.S., rates of primary and secondary (P and S) syphilis increased by $19 \%$ from 2014-2015. While rates have increased among both men and women, men account for more than $90 \%$ of all P and S cases; the majority (83\%) among men who have sex with men (MSM). Likewise, increases in congenital syphilis (CS) have paralleled the national increase in $\mathrm{P}$ and $\mathrm{S}$ syphilis among women.

Methods On January 23-26, 2016, CDC held a consultation with 140 experts in the field of syphilis to discuss current issues, trends, and priority actions in response to increasing syphilis rates. Consultants included experts from academia, local and state health departments, and other federal agencies. The summit included five focus areas; 2 sessions concentrated on congenital and MSM syphilis. Strategies for a syphilis action plan were discussed. Meeting notes were taken during the summit, then independently reviewed, reconciled, and summarised.

Results Several cross-cutting themes emerged: clearer recommendations for better clinical management of syphilis; better diagnostics for detection of active Treponema pallidum infection with need for new testing technologies and strain surveillance; and the need to address CS and MSM (and transgender) data gaps through better coordination between epidemiology, surveillance, lab, and program. Specific to CS, strategies need to address penicillin $G$ manufacturing and supply line shortages; healthcare providers need to test all pregnant women for syphilis at the prenatal visit, the beginning of the third trimester and at delivery, promptly treat and quickly report cases to health departments where all CS cases should be reviewed for missed opportunities in the CS prevention cascade to inform interventions. Strategies relevant to MSM 
include addressing payment and access barriers, developing a sexual healthcare model for men which could include standing orders for frequent syphilis screening for MSM seeking STD or HIV services along with other recommended STD screening, vaccinations and prevention interventions, monitoring adverse outcomes of syphilis in MSM such as neurosyphilis and ocular syphilis, and aligning HIV and syphilis surveillance systems and prevention messages.

Conclusion The prevention of CS and MSM syphilis depend on a successful call to action defining ways that healthcare providers, health departments, communities and policymakers can contribute to syphilis prevention and control.

\section{P6.12 SEX AND TRAVEL: MSM UTILITY - LOCATION BASED SOCIAL NETWORKING/DATING SMART PHONE APPLICATION IN PAKISTAN}

Muhammad Osama. Naz Male Health Alliance, Lahore - Pakistan

\subsection{6/sextrans-2017-053264.663}

Introduction GRINDR is an MSM-specific location-based social networking application for smart phones originally developed as a free service in 2009. Study also shows that 6 Million users logon to GRINDR an average of 8 times a day in 2013. Pakistan has population of over 200 Million people, usage of GRINDR is getting very common in MSM population in Pakistan due to availability of smart phones on economical price also availability of economical Internet packages. Studies showed that one in five travellers had casual sex, and $50 \%$ of these travellers had unsafe sex. One of the review concluded that at least $30 \%-35 \%$ of MSM now use Internet to find sexual partners.

Methods To review previous studies which conducted outside of Pakistan to see whether these applications may be possible tools to enhance HIV/STI prevention interventions within Men who have sex with Men (MSM) community in Pakistan. Results Review showed that GRINDR is an efficient and effective tool for the identification of a targeted high-risk MSM population in Los Angeles who are vulnerable to contract HIV/STI. There was no significant difference between using hookup apps and contracting HIV.

Conclusion During travel, GRINDR is overused in MSM population to allow users to find other men through on-line dating services. This experience from these studies encourages venereologists to explore MSM smartphones applications' ability to target specific sub-groups within Pakistan's MSM population who are vulnerable to contract HIV/STI, also there is a need to conduct further studies by using smart phone recruitment approach.

\section{P6.13 MIDWIVES IN SCHOOLS: A STRATEGY FOR INCREASING STI KNOWLEDGE AND AWARENESS AMONG YOUNG PEOPLE IN CHILE}

${ }^{1}$ Nicole Iturrieta, ${ }^{1}$ Meredith Temple-Smith, ${ }^{2} J a n e$ Tomnay. ${ }^{1}$ Department of General Practice University of Melbourne, Melbourne, Australia; ${ }^{2}$ Department of Rural Health - Centre for Excellence in Rural Sexual Health - University of Melbourne, Melbourne, Australia

\subsection{6/sextrans-2017-053264.664}

Introduction In Chile, sexually transmitted infections (STIs) are a public health problem and require a comprehensive approach for effective control. Although the provision of clinical services has improved; the incidence and prevalence of STIs such as HIV, syphilis and gonorrhoea have remained stable over the last decade. In this study, we investigated healthcare providers' (HCP) understanding of patients' perceptions of STIs and explored which strategies might improve STI control locally.

Methods 48 semi-structured face-to-face interviews were conducted with HCP. A third of the interviews were transcribed verbatim and translated from Spanish to English for thematic analysis, which followed an inductive approach based on grounded theory. Following the identification of themes, remaining interviews were coded utilising a method of constant comparison to highlight concordance and dissonance of participant views.

Results Participants perceived that the majority of patients were not concerned about STIs other than HIV, as campaigns are regularly launched in Chile principally focused on improving HIV awareness. Participants also recognised that symptoms are the primary impetus for patients attending health services and they are less likely to attend for STI prevention. However, HCP in this study also highlighted their work in schools which focuses on primary prevention by improving the sexual health knowledge of young people. There was strong agreement by participants that this was the most appropriate strategy to disseminate STI information to this cohort. Participants proposed that midwives could play a key role by working closely with young people at schools as part of a comprehensive sexual health educational program.

Conclusion We recommend strengthening STI control through continuation of existing activities at PHC centres and enhancing current interventions in schools through a greater investment of resources focused on improving the sexual health literacy of Chilean young people.

\section{P6.14 DETERMINANTS OF CONDOM USE AMONG FEMALE SEX WORKERS IN KENYA: A CASE-CROSSOVER ANALYSIS}

${ }^{1}$ Njeri Mbugua, ${ }^{2}$ Elizabeth Ann Bukusi, ${ }^{3}$ Asunta Wagura, ${ }^{4}$ Elizabeth Ngugi. ${ }^{1}$ Kenya Medical Research Institute/Nairobi University/Kenyatta Hospital/Kenya Women With HIVIAIDS, Nairobi, Kenya; ${ }^{2}$ Kenya Medical Research Institute/Nairobi University, Nairobi, Kenya; ${ }^{3}$ Kenya Network of Women Living With HIVIAIDS, Nairobi, Kenya; ${ }^{4}$ Nairobi University, Nairobi, Kenya

\subsection{6/sextrans-2017-053264.665}

Introduction We evaluated predictors of consistent condom use among female sex workers (FSWs), a core group for controlling the spread of HIV.

Methods In an analysis of data collected in 2004-2005 from 140 Kenyan FSWs who completed questionnaires administered during a baseline study visit and three bimonthly follow-up visits, we used a case-crossover design to identify predictors of consistent condom use during all coital acts in the preceding 2 weeks, overall and by partner type.

Results Participants $(n=140)$ completed the baseline visit and 390 bimonthly follow-up visits. Alcohol use during sex was negatively associated with consistent condom use with helping partners (defined as regular sex partners to whom the woman could go for help or support if needed) (adjusted odds ratio [AOR], 2.6, 95\% confidence interval [CI] 1.0-6.5) but not associated with condom use with other partners. Coital frequency was associated with condom use with other partners 